\title{
Financial Assistance for the Treatment of Schizophrenia in Select Institutions in the Philippines
}

Jonathan P. Guevarra, RM, RN, MAN, ${ }^{1}$ Carl Abelardo T. Antonio, MD, MPH, ${ }^{2,3}$ Kim L. Cochon, RND, MSPH, ${ }^{4}$ Amiel Nazer C. Bermudez, MD, MPH, ${ }^{5,6}$ Fernando B. Garcia, Jr., PhD, ${ }^{2}$ Jorel A. Manalo, PTRP, MPH, ${ }^{7}$ Gary T. Pagtiilan, ${ }^{8,9}$ Ernest Genesis M. Guevara, ${ }^{8}$ Stephanie M. Lao, ${ }^{10}$ and Erwin G. Benedicto, MD, MPH ${ }^{10}$

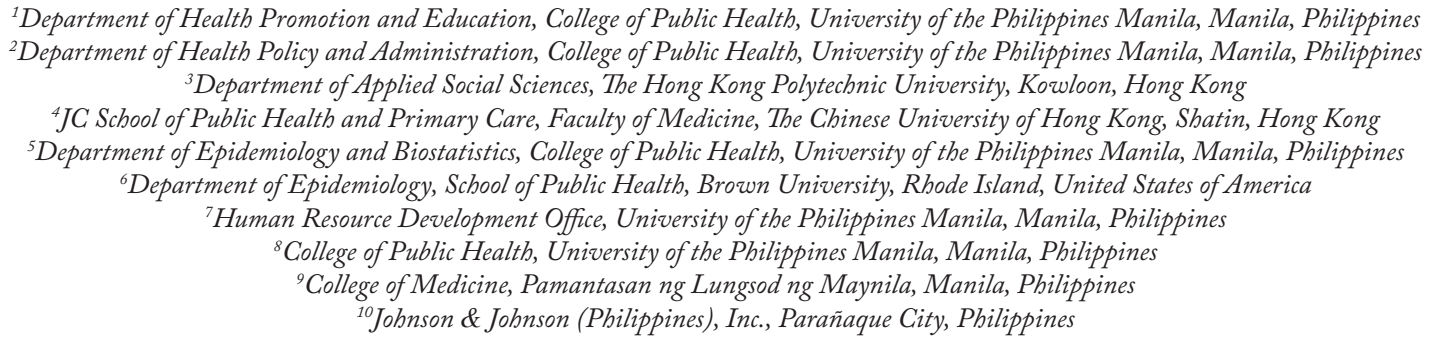

\section{ABSTRACT}

Objective. This paper aims to characterize existing financial assistance available to patients with schizophrenia. Specifically, we described (1) the funding mechanisms for the treatment of patients with schizophrenia; (2) the process for accessing financial assistance; and (3) the experiences of consumers of services of these support mechanisms.

Methods. We employed qualitative techniques using key informant interviews (KII) and focus group discussion (FGD). Key informants were officials from institutions providing or offering financial assistance for patients with any health-related concerns, including schizophrenia. Focus group participants were support group members or caregivers of patients with schizophrenia. Purposive sampling was used to select participants for both providers and consumers of financial assistance or scheme. Topic guides for KII and FGD were used for data collection. Thematic analysis was performed on the qualitative data gathered from the informants and focus group participants.

Results. Securing financial assistance for schizophrenia followed a generally similar process, whether the source is from government offices or civil society organizations, and can be grouped into three main stages: (a) preapplication, (b) application, and (c) post-application. While the process of seeking financial assistance appears to be straightforward, issues were encountered in all of the stages by both providers and recipients alike, namely: (a) Financial assistance as an augmentation to patient resources; (b) Mismatch between demand and service capability; (c) Measures of organizational effectiveness; (d) Health professionals and support groups as "bridges" / "facilitators" to financial assistance providers; (e) Financial and non-financial costs incurred by caregivers in applying for financial assistance; and (f) Recipient-provider relationship as a barrier to the feedback process.

Conclusion. This study provides a glimpse of available financial and other relevant assistance to clients, including clients suffering from schizophrenia. More extensive research covering more organizations, support groups, and caregivers from different parts of the country is recommended.

Key Words: Financial assistance, schizophrenia, Philippines

Corresponding author: Jonathan P. Guevarra, RN, RM, MAN

Department of Health Promotion and Education

College of Public Health

University of the Philippines Manila

625 Pedro Gil Street, Ermita, Manila 1000, Philippines

Email: jpguevarra2@up.edu.ph 


\section{INTRODUCTION}

Mental disorders remain to be considered as among the unrecognized and neglected causes of morbidity and mortality among Filipinos despite the relatively high burden it causes the country. Mental disorders have an estimated prevalence of 87.96 per 100,000 population and a mortality rate of 0.70 per 100,000 population. ${ }^{1,2}$ Among the different mental health disorders, schizophrenia has been identified as a leading diagnosis in outpatient facilities, community inpatient facilities, and mental hospitals, with prevalence rates of $57 \%, 63 \%$, and $71 \%$ for these settings, respectively. ${ }^{3}$

While there are efforts to improve mental health in the country, the national budget allocated towards mental health is mostly (95\%) being utilized for operation, maintenance, and personnel salary in mental hospitals. ${ }^{4,5}$ Additionally, the Philippine Health Insurance Corporation (PHIC) coverage of mental disorders is only limited to short-term in-patient care and treatment for other comorbidities covered by the existing benefits package. ${ }^{6}$ The expenditure for antipsychotic and antidepressant medications, however, requires about 0.46\% (about US\$ 0.035) and 11.14\% (US\$ 0.75), respectively, of the minimum daily wage of Filipinos. ${ }^{3}$ This leaves the economic burden of mental disorders' long-term impact mainly on the families and communities. Prior studies documented the financial strain experienced by families and caregivers of patients with schizophrenia as a predominant concern and source of family burden or "suffering."7-14 Meanwhile, the proportion of households in the Philippines that experience catastrophic expenditure was at $1.5 \%$, which translates to around 1.5 million Filipinos devoting more than $40 \%$ of their income to health care. ${ }^{15}$ This imposes a significant burden to the country by further increasing poverty incidence, which was already at $26 \%$ in the year 2015. ${ }^{16}$ Despite a meager annual average family income of $\$ 14$ per day, the average household out-of-pocket expenditure was estimated at around $\$ 172$ for the year $2012 .{ }^{15,17}$

As with other chronic conditions, the effective management of schizophrenia relies heavily on the continuous adequacy of resources to sustain the costs of long-term and effective relevant healthcare services, medicines, equipment, and materials. The financing shortfall brought about by the lack of available health insurance schemes and the existing gap between healthcare costs and a patient and family's financial capabilities is typically filled-in through monetary or in-kind resources from government institutions (e.g., Philippine Amusement and Gaming Corporation [PAGCOR] and the Philippine Charity Sweepstakes Office $[\mathrm{PCSO}]$ ) and the private sector (e.g., civil society groups and non-government organizations [NGO]). ${ }^{18}$ However, very little is known or has been written about these financing sources. It was in this context that this paper was conceptualized.

We aim to characterize existing financial assistance schemes available to patients with schizophrenia, explicitly identifying (1) the funding mechanisms for the treatment of patients with schizophrenia; (2) the process for accessing financial assistance; and (3) the experiences of consumers of services of these support mechanisms. Our analysis can be used as a starting point for further research for these alternative financing sources and the development of institutional mechanisms to harness the benefits afforded by these financing organizations fully.

\section{METHODS}

We report on the analysis of a subset of data collected from a project that aimed to document and compile a directory of available financial assistance providers for schizophrenia in the Philippines. Specifically, we draw on data from key informant interviews (KII) with three financial assistance providers catering to patients with schizophrenia and focus group discussion (FGD) with one hospital-based schizophrenia patient support group, all located in the National Capital Region. Financial assistance providers were identified through an online search, and interviewees were identified after formal written communication by the project team with the organization's head. Meanwhile, the support group was referred by a psychiatrist advising the project team, and the support group identified the focus group participants from within their membership.

Topics covered by the key informant interview were (a) basic information regarding the assistance such as the source of funding, coverage on treatment, and benefits and limitations; (b) requirements and the process of application for the financial assistance; (c) evaluation of the success of the financial assistance; and (d) challenges and recommendations of the informant in the implementation of the assistance. In addition to these four topics, the focus group discussion also explored on the participants' (e) source of information regarding financial assistance; and (f) experiences and insights on the application, utilization, and extent of financial assistance provided.

Two project team members conducted all interviews and focus group discussion, who proceeded with data collection and audio-recording of the interview and focus group proceeding after securing the participants' consent.

The research assistants transcribed audio-recorded interviews, and a member of the project team reviewed transcriptions for accuracy of the transcription. Transcripts were subjected to thematic analysis, specifically with relevant passages manually coded using the interview topics or discussion as preliminary categories. The coded quotes were then grouped and clustered to identify emerging themes aligned with this paper's aims. To ensure the quality of findings, triangulation by source (i.e., financial assistance providers and recipients) and method (i.e., key informant interviews and focus group discussion) were employed. Further, we subjected the initial findings to a meeting and critique by two psychiatrists with extensive practice in both 
government and private hospitals who also served as advisers of the schizophrenia support group.

Data collection was performed in April 2016, and preliminary analysis was done in July 2016. We reanalyzed the data from July to September 2020 due to feedback received from the anonymous peer reviewers.

This project was funded by Johnson \& Johnson (Philippines), Inc. under the "Patient's Equity to Support Out-of-Pocket Expense Value" project. The funder had no role in data collection and analysis.

\section{RESULTS}

We present our findings in two parts. First, we outline the financial assistance process in broad terms to establish what takes place when a patient or caregiver seeks help for their medical needs from a government office or private organization. This section will serve as the backdrop against which we frame the second part on providers' and recipients' experiences and issues as they move through the financial assistance process.

\section{Financial assistance process}

Securing financial assistance for schizophrenia followed a generally similar process, whether the source is from government offices or civil society organizations, and can be grouped into three main stages: (a) pre-application, (b) application, and (c) post-application (Table 1).

Table 1. Stages and General Steps in Applying for Financial Assistance

Stages

1. Pre-application

2. Application

\begin{tabular}{ll} 
3. Post-application & 1.5. Release of financial assistance \\
& 1.6. Evaluation of service provision \\
\hline
\end{tabular}

The pre-application stage is mainly concerned with identifying the sources of assistance and the subsequent preparation of documents required to avail of said assistance. The usual aid providers mentioned by our informants were the Philippine Charity Sweepstakes Office (PCSO), Department of Social Welfare and Development (DSWD), offices of some Senators, Medical Social Services (MSS) of a hospital, and some non-government organizations (NGOs). Information regarding these sources was typically derived by word of mouth or referrals from other laypersons or healthcare professionals. Information also came from tarpaulins and posts regarding available financial support in rare instances in some healthcare institutions. Each provider requires submission of a set of documents to support the application, which generally fell into three types: (a) request for financial assistance (e.g., handwritten letter from the patient or caregiver stating what form of financial aid is required and the reason for this, completed application form required by the provider); (b) proof of medical condition (i.e., medical/clinical abstract, copies of prescription for medications, a medical certificate from attending physician); and (c) proof of need (i.e., attestation of indigent status issued by the applicant's barangay officials, social case study report from the social welfare unit of the healthcare institution).

Upon completion of the requirements, the request is moved to the application stage. This typically involves the submission of the application packet and processing of the request. Caregivers usually submit the application packet to the financial assistance provider's offices to verify the completeness and subsequent validation of the request done through, for example, interviews with the patient and caregiver, or both, by a social worker or similar officer from the organization. However, in instances where there is an existing cooperative agreement between a healthcare facility and a donor organization, the application stage is usually accomplished by either the attending physician or the healthcare facility's social worker, who files the necessary paperwork through electronic channels. Supposing the application is found to be in order, the request for financial assistance is then processed for approval, a step which can take from as short as one day to as long as a month depending on the urgency of the requested financial assistance, the amount being requested, and completion of internal administrative requirements of the organization (e.g., canvassing/quotation of prices for medicines, routing of disbursement documents for signature by approving authorities). For example, one public charity organization indicated that their expedited timeline is usually the same day as an application for requests amounting to less than Php 10,000.00. It may take about four days for requests larger than this amount.

The post-application stage is when beneficiaries are provided the requested and approved financial assistance. The allocation and distribution of financial aid among patients are generally facilitated through the issuance of checks and guarantee letters directly to the healthcare facility hosting the patient or the assistance provider's partner facility. The checks and guarantee letters state the extent of covered aspects of the patient's treatment or management and the expenses to be covered for the specified treatment and management. Assistance can also be provided in kind, as in the provision of requested medicines to one psychiatric department of a hospital, and very rarely in cash. Release of the requested financial assistance is also typically the success indicator for financial assistance providers. No follow-ups are done on the recipients or patients. However, some patients, caregivers, or attending healthcare professionals voluntarily provide the donor organizations an update once the patient is discharged (e.g., a personal visit to the office, dropping off a "thank you" note, or a phone call from the attending physician). One NGO mentioned soliciting videotaped testimonials from their beneficiaries for documentation purposes. 


\section{Experiences and issues with the financial assis- tance process}

While the process of seeking financial assistance as outlined in the preceding section appears to be straightforward, issues were encountered in all of the stages by both providers and recipients alike (Table 2).

Table 2. Issues with the financial application process

\begin{tabular}{|c|c|c|}
\hline \multirow[b]{2}{*}{ Stage } & \multicolumn{2}{|c|}{ Identified issues } \\
\hline & $\begin{array}{c}\text { Provider } \\
\text { perspectives }\end{array}$ & $\begin{array}{c}\text { Recipient } \\
\text { perspectives }\end{array}$ \\
\hline Pre-application & $\begin{array}{l}\text { Financial assistance } \\
\text { as "augmentation" } \\
\text { to patient resources }\end{array}$ & $\begin{array}{l}\text { Health professionals } \\
\text { and support groups as } \\
\text { "bridges" / "facilitators" } \\
\text { to financial assistance } \\
\text { providers }\end{array}$ \\
\hline Application & $\begin{array}{l}\text { A mismatch } \\
\text { between demand } \\
\text { and service } \\
\text { capability }\end{array}$ & $\begin{array}{l}\text { Financial and non- } \\
\text { financial costs incurred } \\
\text { by caregivers in applying } \\
\text { for financial assistance }\end{array}$ \\
\hline Post-application & $\begin{array}{l}\text { Measures of } \\
\text { organizational } \\
\text { effectiveness }\end{array}$ & $\begin{array}{l}\text { Recipient-provider } \\
\text { relationship as a barrier } \\
\text { to the feedback process }\end{array}$ \\
\hline
\end{tabular}

\section{Financial assistance as an "augmentation" to patient resources}

First, providers stressed that despite the extent of the aid that they can provide, this should still be viewed as an augmentation measure to the expenditures incurred by patients ("We maintain the rule that our financial aid is only to augment the financial capacity of the patient, we cannot shoulder all of the expenses... We only augment. We do not pay all expenses" as stated by one informant). This stance is related to the limited financial resources available to these provider organizations, which, in the case of public charity, can allocate only a specific portion of their budget to aid provision or on the amount raised from fund-raising activities in the case of NGOs. Also, there is a mismatch between available resources and the demand for assistance being received ("... the biggest challenge is that there is never enough..."), especially considering that patients have varying needs in the different phases of their disease process and that most of those requesting assistance do so for disease conditions that require high costs for treatment.

\section{A mismatch between demand and service capability}

Second, NGOs operating on donated funds also face the challenge of managing with limited personnel. One organization, for instance, was only staffed by three individuals, all of whom work on a volunteer and part-time basis. Simultaneously, the secretary and messenger are private employees brought in by the organization's manager. This affects the organization's ability to meet requests lodged with their organization, such that only a limited number of proposals can be accommodated and processed within a day.
Furthermore, monitoring and follow-up of recipients cannot be done anymore. This issue, however, was not explicitly mentioned or raised by our informant from the public charity office.

\section{Measures of organizational effectiveness}

Third, a standard internal action for either a public or private financial assistance provider is the regular audit of the institutions' transactions in their financial assistance provision, submitted to donors or relevant offices. Beyond this, however, the perspective of effectiveness differed between public charities and NGOs. A public charity organization considers the timeliness (i.e., capacity to meet the internal deadline or timeline for approving requests) and responsiveness (i.e., feedback from satisfaction surveys and through the complaints desk) of their financial assistance program as success indicators. The terminal output provides financial assistance to the requesting patient or caregiver, and no further follow-up or monitoring is conducted ("For us, the cycle is completed if payment was done"). NGOs, on the other hand, offered a different perspective. Their leading success indicator is the trust and cooperation their organization receives from other foundations and healthcare facilities and how it translates to increased credibility of their organization and affects their capacity to raise funds from private donors.

Health professionals and support groups as "bridges" / "facilitators" to financial assistance providers

Fourth, information regarding organizations that provide financial assistance is not readily available or accessible in print or online sources. Instead, patients or caregivers rely on other caregivers' referrals in support groups (from "...other patients who have previously availed of the assistance") or information shared by physicians and nurses in the healthcare facility. In addition to being sources of information, physicians were reported to have assisted caregivers in preparing and submitting pertinent documents, and facilitating the patient's enrollment to the financial assistance scheme.

Financial and non-financial costs incurred by caregivers in applying for financial assistance

Fifth, caregivers expressed concern regarding the practicality of obtaining financial aid. The process requires one to queue for long hours, sometimes starting very early in the morning, along with other families seeking financial help from the same organization as only a limited number of applications can be accommodated per day ("You have to be there and fall in line as early as 5 AM or 4:30 AM. Sometimes, if you didn't make it to the cut-off, you need to go back the next day"). The application also entails costs from preparation of documentary requirements, transportation expenses, and missed work opportunities. Thus, the benefits of the financial assistance sometimes only offset the costs 
incurred for application (i.e., in money, time, and effort), dissuading future attempts to seek financial aid ("Seems like it's break-even. Sometimes, that's even a loss for me because I needed to be absent from work. Quite not that practical").

\section{Recipient-provider relationship as a barrier to the feedback process}

Sixth, despite the challenges encountered in the financial assistance application process, there was hesitation on the part of recipients to provide feedback and raise their concerns owing either to their perceived dependent relationship with the organization ("Sometimes, we just keep silent about this since it's not our money and we are just requesting from them"), or concerns about the impact of the feedback on future assistance requests ("It might be difficult to seek assistance from them if we would make this an issue").

\section{DISCUSSION}

This study outlined the financial assistance process in broad terms when a patient or caregiver seeks help for their medical needs from a government office or private organization. These processes include the pre-application stage, which is mainly concerned with the identification of the sources of assistance, and the subsequent preparation of documents that are required to avail of said assistance; the application stage, which involves the submission of the application packet, and processing of the request; and the post-application stage wherein the beneficiaries are provided the requested and approved financial assistance. Both providers and recipients encountered issues in the different stages, which have implications for actual benefits availment, financial assistance program design, and the country's overall health financing policy.

One key finding of this paper is that financial assistance provided by the participating institutions act as support to overall health financing in the country but appears to be especially important for schizophrenia and other conditions that are not adequately covered by the national government, local government, social health insurance, and private sources. The exact contribution of these financing agents is not well-documented in the literature ${ }^{18}$ but has been accepted as part of what can be considered anecdotal evidence. However, we have noted that these organizations' financial assistance is insufficient to support the entire treatment process. Thus, the promulgation of Republic Act No. 11036, otherwise known as the Mental Health Act, in June 2019 is a welcome development as this law aims to make available the outpatient and benefits packages for priority mental health conditions within two years after the implementation of the law's implementing rules and regulations. ${ }^{19,20}$ In the Schizophrenia Outpatient Health Outcomes (SOHO) study done in 10 European countries (Denmark, France, Germany, Greece, Ireland, Italy, the Netherlands, Portugal, Spain, and the UK), it was revealed that a mixture of tax and social insurance funding mechanisms dominate general health care funding in Europe. ${ }^{21}$ These mechanisms in principle promote equity in access to all health care interventions, including those for mental health. However, the study's authors also stated that current resource allocation to mental health care might not entirely reflect mental health disorders. At the time of this writing, it remains to be seen if and how the benefits of financial support for mental health disorders as envisioned in Republic Act No. 11036 will be realized.

Second, health professionals, social workers, and support groups play a critical role in linking beneficiaries and providers, facilitating the financial assistance process in various ways (e.g., locating possible financial assistance providers, accomplishing the needed documentary requirements, submitting supporting documents to the assistance providers). In this way, they fulfill the characteristics of boundary spanners or boundary-spanning agents, individuals within organizations who help transcend the boundaries or divisions that separate work units. ${ }^{22}$ The literature has documented the facilitative function that boundary spanners play in various healthcare and organizational settings but has also noted that they may serve as gatekeepers who may preclude access from others. ${ }^{22-28}$ The facilitative function of these boundary spanners in the local setting for schizophrenia and other conditions should be acknowledged and supported within organizations. For example, the provision of more concrete and up-to-date information on financial assistance can be shared with their patients or clients. Moreover, the informational aspect of the role of these professionals and groups can be "liberated" and transferred to other media such as posters, flyers, or websites that will serve as a freely accessible hub for financing-related information (e.g., assistance providers, coverage, and benefits, availment requirements and procedure) that patients and their families can peruse. Analyzing the boundary spanning role and process in our local healthcare facilities may be a viable pathway for future research.

Lastly, despite the possible benefits, the challenges in obtaining assistance from providers serve as a deterrent for patients and their families who wish to avail of the offered financial support. Thus, it can be argued that perceived or actual organizational barriers further compound the financial barrier that patients and their families are trying to overcome by seeking financial assistance from funding organizations. While it is beyond this paper's remit to reflect on organizational-level factors as healthcare access barriers, published sources have extensively discussed this issue. ${ }^{29-32}$ What we wish to point out are two implications of this finding. First, there is a need for financing organizations to consider streamlining their benefits availment procedures. One good practice that we noted was establishing formal linkages between healthcare facilities and funding organizations. This is because a unit or office facilitates the hospital's application, and the financial assistance is directly transferred between the donor and recipient organizations. This approach 
alleviates the burden that patients and families must contend with when attending to the administrative requirements and procedures of requesting financial assistance. Second, creating a centralized hub that will pool and process all financial assistance requests and grants may be explored by financing organizations to minimize redundancy. An extreme and ideal example is the pooling of funds from taxation, social health insurance premium payments, and revenues from PCSO and PAGCOR to finance the delivery of population-based services as contemplated in Republic Act No. 11223 (Universal Health Care Act). However, we note that this may not be an entirely feasible arrangement for private sector financing providers. We hasten to add that the best scenario would be a situation where patients and their families will no longer have to secure financial aid from various sources because healthcare is already fully guaranteed and supported by a third-party payer.

Results of this study must also be interpreted in light of some limitations encountered while conducting the survey. First, this study covered only a small number of organizations in the National Capital Region, the Philippines, that assist patients suffering from chronic conditions, including schizophrenia. Other organizations in other parts of the country also provide assistance not covered by this present study. Although other organizations were identified in the study, only those who consented to participate were covered, yielding only a small number of key informants. Second, as for the focus group participants, although there were other support groups contacted for the study, only a small number of support group members agreed to participate in the discussion. With this, it is highly possible that we may not have gathered enough evidence of the actual experiences of other support group members in availing of the much-needed assistance for their loved ones suffering from the chronic mental health condition. Third, the data presented in this study came from qualitative techniques only. It would have have been better if quantitative methods have supplemented the qualitative data to have a more comprehensive picture of the financial assistance being provided to the needy clients.

\section{CONCLUSION}

This study provides us a picture of the financial assistance process followed by the financial assistance seekers. Securing financial assistance for schizophrenia followed a generally similar process, whether the source is from government offices or civil society organizations, and can be grouped into three main stages: (a) pre-application, (b) application, and (c) post-application. The issues encountered in all of the steps by both providers and recipients alike were: (a) Financial assistance as an "augmentation" to patient resources; (b) Mismatch between demand and service capability; (c) Measures of organizational effectiveness; (d) Health professionals and support groups as "bridges" / "facilitators" to financial assistance providers; (e) Financial and non-financial costs incurred by caregivers in applying for financial assistance; and (f) Recipient-provider relationship as a barrier to the feedback process.

\section{Acknowledgment}

Completion of this project was realized through the generous contribution of the members of the Technical Advisory Group (Dr. Ma. Lourdes Rosanna E. de Guzman, Dr. Razel Nikka Hao, Dr. Ma. Cynthia R. Leynes, Dr. Hermogenes J. Monroy III, Dr. Melanie Coronel Santillan, and Dr. Madeleine R. Valera) who guided the implementation of the PESO Value Project from which this paper has been derived. We are also grateful for the technical support provided by project assistants (Mel Christian C. Bilbao, Maria Thea L. Cacal, Dondiego Eleazar G. Casanova, Diana Francesca G. Gepte, and Reah Jilda C. Ondona), and the the administrative support rendered by Mrs. Maria Bernadette P. Idjao (College of Public Health, University of the Philippines Manila), and Ms. Rosario P. Vacal (University of the Philippines College of Public Health Foundation, Inc.).

\section{Statement of Authorship}

CTA - conceptualization and design, data collection, data analysis, report writing, substantial revision to the manuscript after peer review, approval of the final version submitted.

JPG - design, data collection, data analysis, report writing, substantial revision to the manuscript after peer review, approval of the final version submitted.

JAM, GTP, EMG - data collection, data analysis, report writing, approval of the final version submitted.

All other authors - data analysis, report writing, approval of the final version submitted.

\section{Author Disclosure}

SML and EGB are employees of Johnson \& Johnson (Philippines), Inc., which supported this project's implementation. CTA, ACB and KLC received grants and professional fees from Johnson \& Johnson (Philippines), Inc. outside of the submitted work. All other authors declare no conflict of interest.

\section{Funding Source}

This project was funded by Johnson \& Johnson (Philippines), Inc. under the "Patient's Equity to Support Out-of-Pocket Expense Value" project. The funder had no role in data collection and analysis.

\section{REFERENCES}

1. Yap J, Reyes C, Albert JR, Tabuga A. Preliminary results of the survey on PWDs conducted in selected Metro Manila cities (Discussion Paper Series No. 2009-025). Makati City: Philippine Institute for Development; 2009.

2. Department of Health. The Philippine Health Statistics 2010. Manila: DOH, 2010. 
3. World Health Organization and Department of Health. WHOAIMS Report on Mental Health System in The Philippines. Manila: WHO Philippines Office and DOH, 2007.

4. Baxter AJ, Patton G, Scott KM, Degenhardt L, Whiteford HA. Global epidemiology of mental disorders: what are we missing? PLoS One. 2013 Jun 24;8(6):e65514. doi: 10.1371/journal.pone.0065514.

5. World Health Organization. Mental Health Atlas 2011 Country Profiles: Philippines. Geneva: WHO, 2011.

6. Philhealth Circular No. 09, s. 2010, Coverage Rules for Psychiatric Conditions Requiring Admission, 22 February 2010.

7. Cornwall PL, Scott J. Burden of care, psychological distress and satisfaction with services in the relatives of acutely mentally disordered adults. Soc Psychiatry Psychiatr Epidemiol. 1996 Nov;31(6):345-8. doi: 10.1007/BF00783423.

8. Sethabouppha H, Kane C. Caring for the seriously mentally ill in Thailand: Buddhist family caregiving. Arch Psychiatr Nurs. 2005 Apr;19(2):44-57. doi: 10.1016/j.apnu.2005.02.004.

9. Chien WT, Chan SW, Morrissey J. The perceived burden among Chinese family caregivers of people with schizophrenia. J Clin Nurs. 2007 Jun;16(6):1151-61. doi: 10.1111/j.1365-2702.2007.01501.x.

10. Hou SY, Ke CL, Su YC, Lung FW, Huang CJ. Exploring the burden of the primary family caregivers of schizophrenia patients in Taiwan. Psychiatry Clin Neurosci. 2008 Oct;62(5):508-14. doi: 10.1111/j. 1440-1819.2008.01843.x.

11. Chan SW. Global perspective of burden of family caregivers for persons with schizophrenia. Arch Psychiatr Nurs. 2011 Oct;25(5): 339-49. doi: 10.1016/j.apnu.2011.03.008.

12. Zhang Z, Deng H, Chen Y, Li S, Zhou Q, Lai H, Liu L, Liu L, Shen W. Cross-sectional survey of the relationship of symptomatology, disability and family burden among patients with schizophrenia in Sichuan, China. Shanghai Arch Psychiatry. 2014 Feb;26(1):22-9. doi: 10.3969/j.issn.1002-0829.2014.01.004.

13. Shamsaei F, Cheraghi F, Bashirian S. Burden on Family Caregivers Caring for Patients with Schizophrenia. Iran J Psychiatry. 2015 Sep;10(4):239-45.

14. Yu Y, Liu ZW, Tang BW, Zhao M, Liu XG, Xiao SY. Reported family burden of schizophrenia patients in rural China. PLoS One. 2017 Jun 19;12(6):e0179425. doi: 10.1371/journal.pone.0179425.

15. Ulep VG, Dela Cruz NA. Analysis of Out-of-Pocket Expenditures in the Philippines. Philippine Journal of Development. 2013:XL (1-2). Available from https://dirp3.pids.gov.ph/webportal/CDN/ PUBLICATIONS/pidspjd13-oop\%20expenditures.pdf

16. Philippine Statistics Authority. 2015 First Semester Official Poverty Statistics. [Internet] 2015. [Cited May 5, 2016.] Available from: https://psa.gov.ph/content/poverty-incidence-among-filipinosregistered-263-first-semester-2015-psa

17. Philippine Statistics Authority. 2012 Income and Expenditure. [Internet] 2012. [Cited May 5, 2016.] http://psa.gov.ph/content/ 2012-fies-statistical-tables

18. Dayrit MM, Lagrada LP, Picazo OF, Pons MC, Villaverde MC. The Philippines Health System Review. Vol. 8 No. 2. New Delhi: World Health Organization, Regional Office for South East Asia; 2018.

19. Republic Act No. 11036. [Internet] [Cited September 16, 2020]. Available from: https://www.officialgazette.gov.ph/downloads/2018/ 06jun/20180620-RA-11036-RRD.pdf
20. Department of Health. Implementing Rules and Regulations of Republic Act No. 11036. [Internet] [Cited September 16, 2020]. Available from: https://www.doh.gov.ph/sites/default/files/health_ advisory/IRR\%20of\%20RA\%2011036.pdf

21. Knapp M, Novick D, Genkeer L, Curran CM, McDaid D, \& SOHO Study Group. Financing health care in Europe: context for the Schizophrenia Outpatient Health Outcomes Study. Acta Psychiatr Scand Suppl. 2003;(416):30-40. doi: 10.1034/j.1600-0447.107. s416.1.x.

22. Nasir L, Robert G, Fischer M, Norman I, Murrells T, Schofield P. Facilitating knowledge exchange between healthcare sectors, organisations and professions: a longitudinal mixed-methods study of boundary-spanning processes and their impact on healthcare quality. Southampton (UK): NIHR Journals Library; 2013 Oct. [Cited September 16, 2020]. Available from: https://www.ncbi.nlm.nih. gov/books/NBK262952/

23. Aungst $\mathrm{H}$, Ruhe M, Stange KC, Allan TM, Borawski EA, Drummond CK, Fischer RL, Fry R, Kahana E, Lalumandier JA, Mehlman M, Moore SM; PHAB Staff and Writing Committee; PHAB Cleveland Advisory Committee. Boundary spanning and health: invitation to a learning community. London J Prim Care (Abingdon). 2012;4(2): 109-115. doi: 10.1080/17571472.2012.11493346.

24. Haas A. Crowding at the frontier: boundary spanners, gatekeepers and knowledge brokers. J Knowl Manag. 2015;19(5): 1029-1047. doi: 10.1108/JKM-01-2015-0036.

25. Sheikh K, Schneider H, Agyepong IA, Lehmann U, Gilson L. Boundary-spanning: reflections on the practices and principles of Global Health. BMJ Glob Health. 2016;1:e00058.

26. Hunt CM, Spence M, McBride A. The role of boundary spanners in delivering collaborative care: a process evaluation. BMC Fam Pract. 2016 Jul 29;17:96. doi: 10.1186/s12875-016-0501-4.

27. Kislov R, Hyde P, McDonald R. New game, old rules? Mechanisms and consequences of legitimation in boundary spanning activities. Org Stud. 2017;38(10):1421-1444. doi: 10.1177/0170840616679455.

28. Kislov R. Selective permeability of boundaries in a knowledge brokering team. Public Adm. 2018;96:817-836. doi: 10.1111/padm.12541.

29. Kedia S, Ward KD, Digney SA, Jackson BM, Roark KS, Boyd SW. Organizational barriers to receiving quality health care: A qualitative study among lung cancer patients and caregivers. J Clin Oncol. 2014;32(30 suppl):76. doi: 10.1200/jco.2014.32.30_suppl.76.

30. Huot S, Ho H, Ko A, Lam S, Tactay P, MacLachlan J, Raanaas RK. Identifying barriers to healthcare delivery and access in the Circumpolar North: important insights for health professionals. Int J Circumpolar Health. 2019 Dec;78(1):1571385. doi: 10.1080/ 22423982.2019.1571385.

31. Nisingizwe MP, Tuyisenge G, Hategeka C, Karim MS. Are perceived barriers to accessing health care associated with inadequate antenatal care visits among women of reproductive age in Rwanda? BMC Pregnancy Child. 2020;20:88 doi: 10.1186/s12884-020-2775-8.

32. Fante-Coleman T, Jackson-Best F. Barriers and facilitators to accessing mental healthcare in Canada for black youth: A scoping review. Adolescent Res Rev. 2020;5:115-136. doi: 10.1007/s40894-02000133-2. 